\title{
Diversity Now! Sequins, Style \& the End of Gender with Dr. Madison
} Moore

\author{
By Rachel Rammal
}

KEYWORDS:

FABULOUS

POLITICS OF STYLE

FASHION AS PROTEST

CREATIVITY

\section{Abstract}

Diversity Now! is an annual lecture series hosted by the Centre for Fashion Diversity and Social Change at Ryerson University in Toronto, Canada. This lecture series explores how individuals have used fashion as a means to inspire social change and political advocacy in their personal lives, their community, or the fashion industry. The 2019 guest lecturer was Dr. Madison Moore, an artist-scholar, DJ, and Assistant Professor of Gender, Sexuality and Women's Studies at Virginia Commonwealth University. In this seventh series lecture, Moore discussed the journey and research behind his recent book Fabulous: The Rise of The Beautiful Eccentric (2018). Drawing on autobiography, anecdotal evidence, and interviews, Moore took his audience on a journey from his childhood in Ferguson, Missouri, to the night scene in New York, London, and Berlin, with an emphasis on Vogue Balls and catwalks. While Moore's lecture drew on various sources, his message was unequivocal: style and clothes have the power to inspire social change. 


\section{JOURNEY OF THE BOOK \\ FABULOUS: THE RISE OF THE \\ BEAUTIFUL ECCENTRIC (2018)}

Madison Moore's 2019 Diversity Now! lecture was far from conventional. This fact became clear from the moment Moore greeted the audience whilst attending to his skincare regimen - he welcomed the auditorium as he massaged coconut oil onto his legs and arms, instantly breaking through the academic "fourth wall." Throughout the lecture, the audience also gained privileged access to his sartorial transformation, as Moore gradually traded clothing items belonging to the realm of heteronormative masculinity, such as a black crew neck and black pants, for more ostentatious items, belonging to what Moore emphatically refers to as "fabulous" "Sequins, Style \& the End of Gender").'

During the first part of the lecture, Moore shared the journey and research behind his recent book Fabulous: The Rise of The Beautiful Eccentric (Figure 1). In his words, the book marries autobiography, cultural criticism, observation, and interviews. Although the book is based on his PhD dissertation completed at Yale in American Studies (2012), Moore shares that the subsequent years spent in London significantly shaped the book. In London, he was able to see "fabulousness" in real time, in the night time at the clubs of Dalston, on the 
streets of East London, on the night bus, and in little glimpses in Soho. Sharing a powerful excerpt from the first chapter of the book, Moore reads aloud:

This is a very personal book. There have been days in my life when I've felt like an outsider, a Black queer error, and it seemed like I couldn't go on without completely falling apart. I get bogged down by the stresses of living while Black, working while Black, and loving while Black, but just when I felt like there was no way out of the depression, with its usual ebbs and flows, fashion and style were always there to lift me up. A little turquoise sequined jacket here, a black floorlength maxi skirt there. Every day fashion and style help me remember that my voice matters. I don't get dressed because I want to be stared and pointed at on the subway or while walking down the street. I would love to live in a world where I could wear whatever I wanted without getting verbally harassed, being followed, or fearing for my safety. But that's not the world we live in. Our world constantly reminds me that I shouldn't exist, so I dress the way I do to scream that I am here. Style lets me tell you about my vision of the world and my dreams for the day, even if the structures that produce my depression don't evaporate just because I'm wearing my favorite sequined jacket. At least I can wear it and say to myself: Today is going to be a good day. (27-28) 


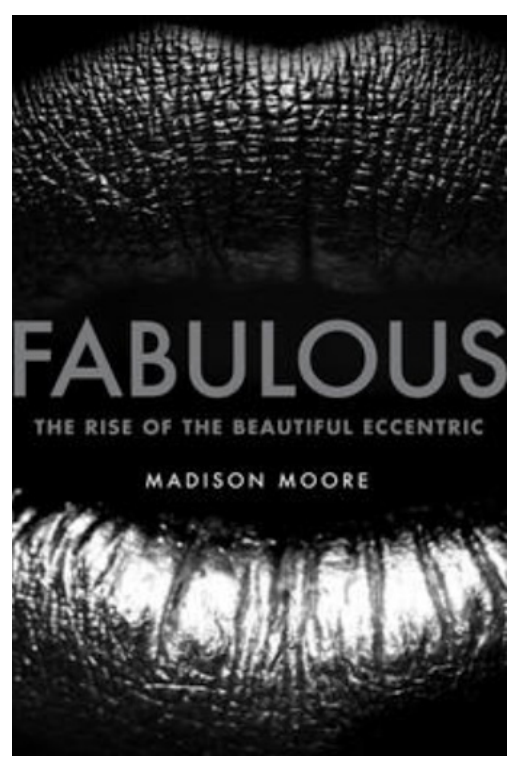

Figure 1. Fabulous: The Rise of the Beautiful Eccentric book cover. Madison

Moore, Fabulous: The Rise of the Beautiful Eccentric, Yale University

Press, 2018.
According to Moore, this book is an attempt to tell the complicated story of how marginalized people turn to creativity, ideas, and imagination in order to assert themselves in worlds and spaces from which they have been historically excluded and dehumanized. Expanding on his vision of style, Moore explained how, to him, style is an attitude - a reaction to oppression. His interest in fabulousness is heavily inspired by the work of Joseph Beam, an African-American gay rights activist and cultural critic whose scholarship pertains to the marginalization of black gay males, specifically in the context of the AIDS epidemic in the 1980s. Citing Beam's definition of fabulousness, Moore reads: "fabulousness points to culture fugitives or aesthetic fugitives, folks who flee from systems, structures, or hierarchies that oppress us all, making themselves from scratch" ("Sequins, Style \& the End of Gender"). Beam challenges common conceptions of 
fabulousness as belonging to the realm of the glamourous or luxurious. Similarly, for Moore, "the most fabulous people create magic out of the mundane, and that's the point" ("Sequins, Style \& the End of Gender"). Through this part of the lecture, Moore also emphasizes how important it was for him to write a book using accessible language. He asserts, "I didn't want to write a book about queer marginalized people that included them in the narrative but excluded them from access to the book." Nonetheless, he admits that this book was not easy to write, and shares that by overcoming recurrent episodes of self-censorship, this book was a symbol of what it looks like to "choose yourself at last" ("Sequins, Style \& the End of Gender").

As he removes his black crew neck, black pants, and shoes to reveal underneath a fitted black shirt and glossy leather pants, Moore rhetorically asks a question he is often on the receiving end of: "Will this book make you fabulous?" The short answer is no. For Moore, "fabulousness is less about a particular style, or look," he explains, and "more a means of giving up on the use of play-acting, make-believe, and pretending to follow the rules. If you realize how you police yourself, that's fabulous" ("Sequins, Style \& the End of Gender").

\section{FERGUSON, MO: THE ROOTS OF FABULOUS}

Moore's journey to fabulousness started in Ferguson, Missouri, a working-class Black suburb in the north of St. Louis. According to Moore, during his childhood years, Ferguson was not particularly notable, and had yet to become infamous for its police brutality and anti-blackness in the United States. In this "ordinary" town, raised in a household that adhered to a politic of Black respectability, Moore stood out as fabulous. Moore shares that despite the harassment he faced on his walks to the Quick Trip gas station on West Forrest Avenue, expressing himself through clothes in the public sphere served as an inherently transgressive task: "I didn't realize that each time I took this walk to the Quick Trip, I was also seizing my own space, reclaiming my time." ("Sequins, Style \& the End of Gender"). When the gas station burned down, Moore interpreted it as an act of protest, symbolically mirroring his own act of dissent.

He also shares that from a young age, he had difficulty conforming to the expectations of respectable style instilled by his family. Upon reflecting on a portrait of him and his grand-mother, taken minutes after an argument about a suit outfit imposed on Moore, he 
revealed that to him, the respectable style emulated by him and his grandmother had less to do with institutional white passing, and more with securing personhood: "Black people have long been positioned against white beauty standards and seen as grotesque humans or just plain ugly, and so here, their respectable style is in fact a demand to be seen as equal, on equal terms" ("Sequins, Style \& the End of Gender"). Embracing the freedom to be strange, in Moore's words, can serve as a utilitarian strategy.

\section{POLITICS OF STYLE}

Style as protest is a quintessential theme of the book and central to Moore's philosophy of fabulousness. Using style to challenge normativity is a conscious decision according to Moore, a commitment that requires you to "create yourself everyday." During this part of the lecture, Moore discusses the politics of style, specifically what it means for individuals on the margins to dress as a political act. He challenges mainstream dismissals of fashion as a frivolous pursuit and argues that being able to not care about how you dress is a form of privilege. As Moore puts it, this privilege of blending consists of "being below the radar and going undetected, unnoticed, unbothered," and how ultimately, "that is safe." ("Sequins, Style $\&$ the End of Gender").

Most importantly, Moore frames his perspective within a commitment to a politic of optimism, creativity, and aesthetics. According to him, the narratives explored in Fabulous are embedded in creativity over victimhood. In his words, "we only talk about Black bodies when we're dying, not when we're thriving." ("Sequins, Style \& the End of Gender"). In this book, Moore aims to transcend these damage-centered narratives by asking questions that shift the locus to the transformative power of dress. His inquiry is fueled by questions such as: "What is it about dress that leads to such freeing, eye-opening, beautiful, and transformative experiences?" To answer this question, Moore drew on the Fabulous Fashion exhibition curated by Kristina Haugland, which took place at the Philadelphia Museum of Art from October 2018 to March 2019. Moore pointed to the incorporation of a ball and runway show hosted by the exhibition, entitled "Fabulous Fashions of Ballroom," held in partnership with the POSSE project in January 2019, where queer people of colour in Philadelphia were given a platform to speak with their bodies and style about the work that they do (see https://philamuseum.org/exhibitions/2020/873.html and https://www.inquirer.com/entertainment/ philadelphia-art-museum-ball-lgbtq-ballroom-dance-culture-20190123. $\underline{\mathrm{html}}$ for more information on the exhibition and ball). 


\section{POLITICS OF FABULOUSNESS}

Building on the concept of ethical self-making, Moore argues that the politics of fabulousness engender "a spectacular appearance founded on a story-telling practice, as well as a poetics of the self that is largely practiced by brown, queer, and other marginalized bodies." Admittedly, he explains that his topic of research raises a lot of questions. Not completely aware of the parametres of fabulousness, people often ask him: "Isn't fabulousness just about gay men doing femininity?" To answer this, he draws on a passage from his interview with performance artist Alok Vaid-Menon. According to Vaid-Menon, this question stems from a hegemonic assumption that we live in a transmisogynistic binaristic world, where gay men are not allowed to live their own femininity. Consequently, Vaid-Menon argues, gay men are expected to "embody the femininity of cis women because they are not allowed to have it themselves." ("Sequins, Style \& the End of Gender").

\section{HOW DO WE END GENDER?}

Moore states that what bothers him the most about gay misogyny is that to get noticed, gay men often have to suppress feminine aspects of themselves, and instead, he invites the audience to reflect on another important question which arose from the Vaid-Menon interview: "What feminine part of yourself did you have to destroy to survive in this world?" ("Sequins, Style \& the End of Gender"). While simultaneously putting on a sequin skirt, Moore presents several fashion labels committed to transcending binary views of gender. These include, but are not limited to, UY Studio in Berlin, a label that does not design for gender; Syro, a brand that creates shoes for larger feet; and Opulence, a queer-techno-space and art collective where Moore serves as the creative director and resident DJ. 


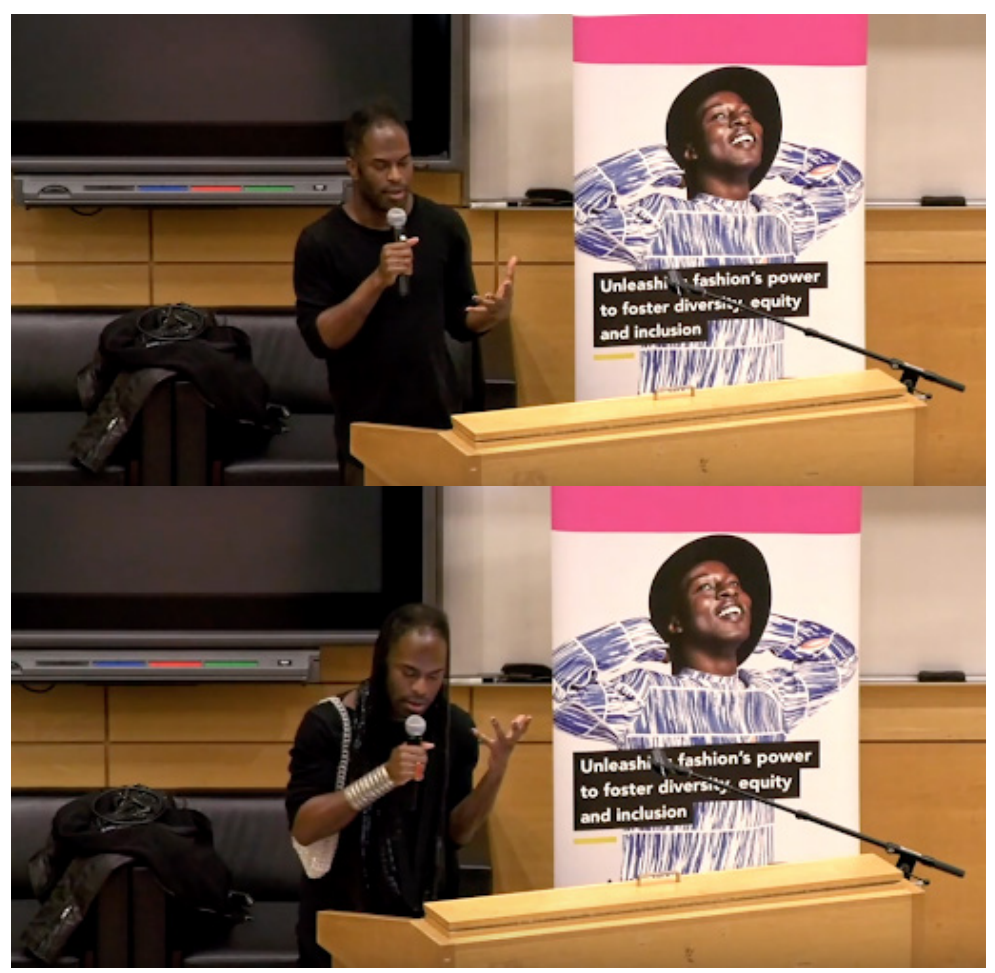

Figure 2. Dr. Madison Moore during his presentation for the seventh annual Diversity NOW! lecture. 5 March 2019, Ryerson University, Toronto, Ontario.

According to Moore, the world of fashion is increasingly attempting to end gender, however this mandate is not limited to labels nor the industry. His biggest inspirations, he argues, were ordinary individuals who dabbled in fabulousness. Drawn to violin since his early years, Moore shares that he was never exposed to other queer concert violinist until one evening at the Stone, where Asian queer violist Leopold was performing, an inspiring moment for Moore. Now wearing an infinity glitter veil, a large metallic bracelet, several rings, and a mesh purse, Moore cautions that taking fabulousness as political action is risky (Figure 2). However, when done right, the work is highly optimistic and liberating. More importantly, he claims, fabulousness is "real time cultural theory," which forefronts creativity over victimhood ("Sequins, Style \& the End of Gender"). 


\section{CONCLUSION}

Moore concludes with a serious remark about fabulousness: "When you see someone in a fabulous look, know that they are dressed out of this world, because they are leaving it behind." Moore summarizes fabulousness as a world-making practice which offers a creative response to living in a constant state of emergency, in response to one's nonconformity. By transcending damage-centered narratives, Moore stresses that his research is about the process whereby brown, queer, and trans bodies, or as Joseph Beam calls them "aesthetics fugitives," use fabulousness to turn their status into pathbreaking and generative creativity, art, music, and performance ("Sequins, Style \& the End of Gender"). This fabulous freedom takes place in the crevasses - nightclubs, cabarets, catwalks, and music venues - or anywhere outside the traditional artistic and cultural institutions that have historically excluded them. Closing the lecture as unconventionally as it began, Moore invites the audience to stand up and join him on the stage-now turned-dancefloor, and the audience obliges.

On the one hand, Moore's lecture made salient the transcendental power of dress beyond the confines of gender. On the other, his rich delivery - drawing on a variety of artistic and communicative media — afforded the audience a glimpse into academia's potential for knowledge production and distribution once scholars dare transgress the confines of traditional scholarship.
To watch Moore's lecture in its entirety online, you can access the Centre for Fashion Diversity and Social Change's YouTube channel here.

This year's eighth annual Diversity NOW! lecture will be taking place this month, on

Tuesday, March 10th, 2020 at 6:30 PM with Founder and Creative Director of CHROMAT, Becca McCharen-Tran. Follow the Centre for Fashion Diversity and Social Change on Twitter at @ ryersonFDSC and on Instagram at @fashionsocialchange for more details on this year's Diversity NOW! lecture. 
WORKS CITED

"Diversity NOW! Sequins, Style \& the End of Gender, with Dr. Madison Moore." Centre for Fashion Diversity and Social Change, https://www.ryerson.ca/fashion/stories-events/2019/03/diversi ty-now $/$.

Moore, Madison. Fabulous: The Rise of the Beautiful Ecccentric. Yale University Press, 2018.

Moore, Madison. "Sequins, Style \& the End of Gender." Diversity Now!, The Centre for Fashion Diversity \& Social Change, 5 March 2019, Ryerson University, Toronto, ON. Guest Lecture.

Moore, Madison. "Sequins, Style \& the End of Gender: A Lecture by Dr. Madison Moore (Diversity NOW! 2019)." YouTube, uploaded by the Centre for Fashion Diversity \& Social Change, 10 May 2019, https://www.youtube.com/watch?v=CO-mOlIbk7g. 


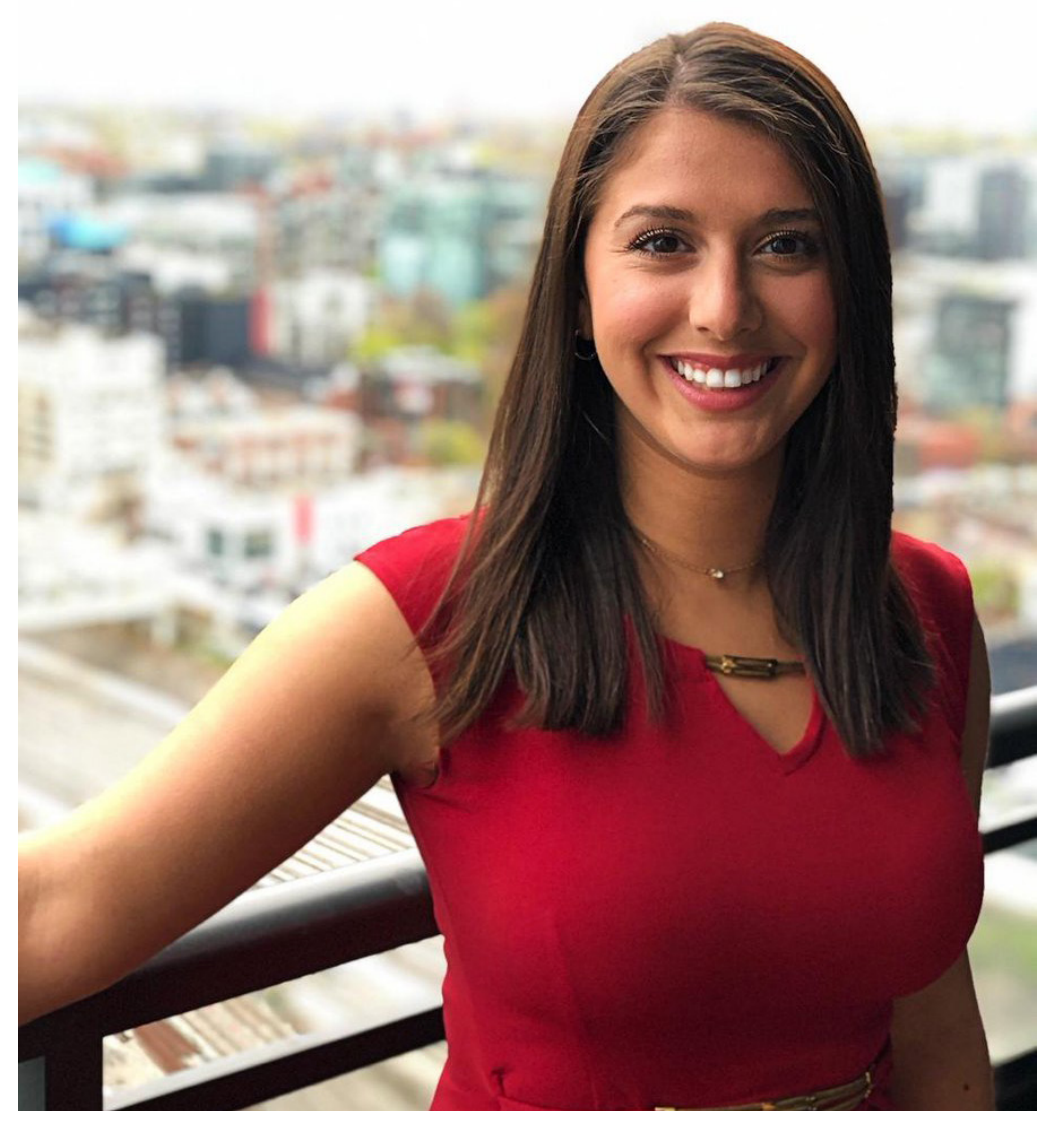

RACHEL RAMMAL is an MA Candidate in the Fashion program at Ryerson University and a former editorial intern at Fashion Studies. Originally from Montreal, Quebec she obtained her undergraduate degree in Psychology (Honours) from Concordia University. Growing up in Quebec, she witnessed the hostile sociopolitical climate surrounding the divisive discourse on religious minorities, identity, and dress. When this discourse culminated with Quebec's recent adoption of Bill 21-a secular policy prohibiting public servants from wearing religious symbols on duty-Rachel was determined to pursue this line of inquiry. Framed within a discourse on values, Bill 21 is reasoned to address concerns of proselytizing and neutrality_both unsupported by empirical evidence. In her current research, Rachel problematizes these tenets using critical discourse analysis, in order to expose the ideological assumptions underlying Bill 21. With an emphasis on the Muslim veil, she explores how current narratives of belonging, identity, and gender equality contribute to the disenfranchisement of religious minorities in Québec, specifically veiled Muslim women whom the bill disproportionately impacts.

\section{Article Citation}

Rammal, Rachel. "Diversity Now! Sequins, Style \& the End of Gender with Dr. Madison Moore." Fashion Studies, vol. 2, no. 2, 2020, pp. 1-11, https://www.fashionstudies.ca/sequins-style-and-the-endof-gender-with-dr-madison-moore, https://doi.org/10.38055/FS020205. 